\title{
Stochastic Modeling of Inter \& Intra Stage Dependent Cancer Growth under Chemotherapy through Trivariate Poisson Processes
}

\author{
P. Tirupathi Rao ${ }^{1}$, B.N. Naveen Kumar ${ }^{2}$, J. Jayabharathiraj ${ }^{3}$ \\ ${ }^{183}$ Dept. of Statistics, Pondicherry University, Puducherry-605014 \\ ${ }^{2}$ Dept. of Statistics, S.V. University, Tirupati - 517502 \\ 11drtrpadi@gmail.com, 2nav.msc@gmail.com, 3.jayabharathi8@gmail.com
}

\begin{abstract}
Keywords: Stochastic Modeling, Inter \& Intra Stage Dependent Cancer Growth, Trivariate Poisson Processes, Stochastic differential equations
\end{abstract}

\begin{abstract}
This study has proposed a Stochastic Model for cancer growth under chemotherapy with the assumptions of the growth, transition and loss parameters of different stages are inter and intra dependent. A trivariate Poisson process approach has been adopted for modeling the three stage cancer growth by considering the stages of cells in the tumor namely normal cell, mutant cell and malignant cell in the presence and absence of chemotherapy during time ' $t$ '. Stochastic differential equations were obtained and the three dimensional joint probability functions along with related statistical measures were derived. Model behavior was analysed through numerical data.
\end{abstract}

\section{Introduction}

The spread of cancer is more vigorous when a normal cell will transformed in to a mutant and further to a malignant cell. The growth, spread and loss processes of different types of cells are purely random and influenced by many known and unknown factors. The cell division and control mechanism of cancerous cells are out of the genetic instructions of any living body. Continuous proliferation of cells within each stage, transformation of cells from one stage to another stage leads to enormous growth within the limited membrane structures of a tissue may cause the formation of tumours. Development of secondary and invasion of cancerous cells through metastasis is again subject to many random issues and uncertainties. Usually the violation of genetic instruction of the cell will be initiated with conversion of a normal cell in to a typical and erratic behaved cell. Further, this erratic behaved/ mutant cell will have a faster growth of division as well as continuous and unending proliferation leads to formation of malignant cell. Hence, the cell division behaviour is varying from one stage to other stage.

Quantification of cancer growth through the mathematical models was initiated by Mayneord (1932). Tumor resistance to chemotherapy by Coldmann et al. (1983), effects of drug resistance in the presence of chemotherapy by Birkhead et al. (1984), chemotherapy of experimental tumors by Coldman et al. (1986), cancer progression and response of chemotherapy by Sandeep sanga et al. (2006), system of differential equations for the control of tumor cells growth by Costa et al. (1995), Phase-space analysis of tumor growth with an immune response and chemotherapy by De pillis et al. (2003), cancer cell growth with spontaneous mutation and proliferation, inactivation of allele genes and under chemotherapy by Tirupathi Rao et al. (2004a, 2004b, 2004c), cancer growth with and without chemotherapy using bi-variate Poisson process by Madhavi et al. (2011) are some significant contributions in modeling the cancer growth using mathematical and stochastic models.

Stochastic modeling on pathophysiology of cancer and its Biology is more appropriate to study the cancer growth and loss processes as it is influenced by many uncertain factors. This study is on stochastic modeling of cancer cell growth in three stages namely normal cell, mutant cell and malignant cell by using trivariate Poisson process in chemotherapy. The process of presence and absence of drug with indexed variables is introduced by assuming the growth of tumor during drug administration and drug vacations are complementary. This model is useful to study the growth of cancer cell as overall phenomena of chemotherapy. 


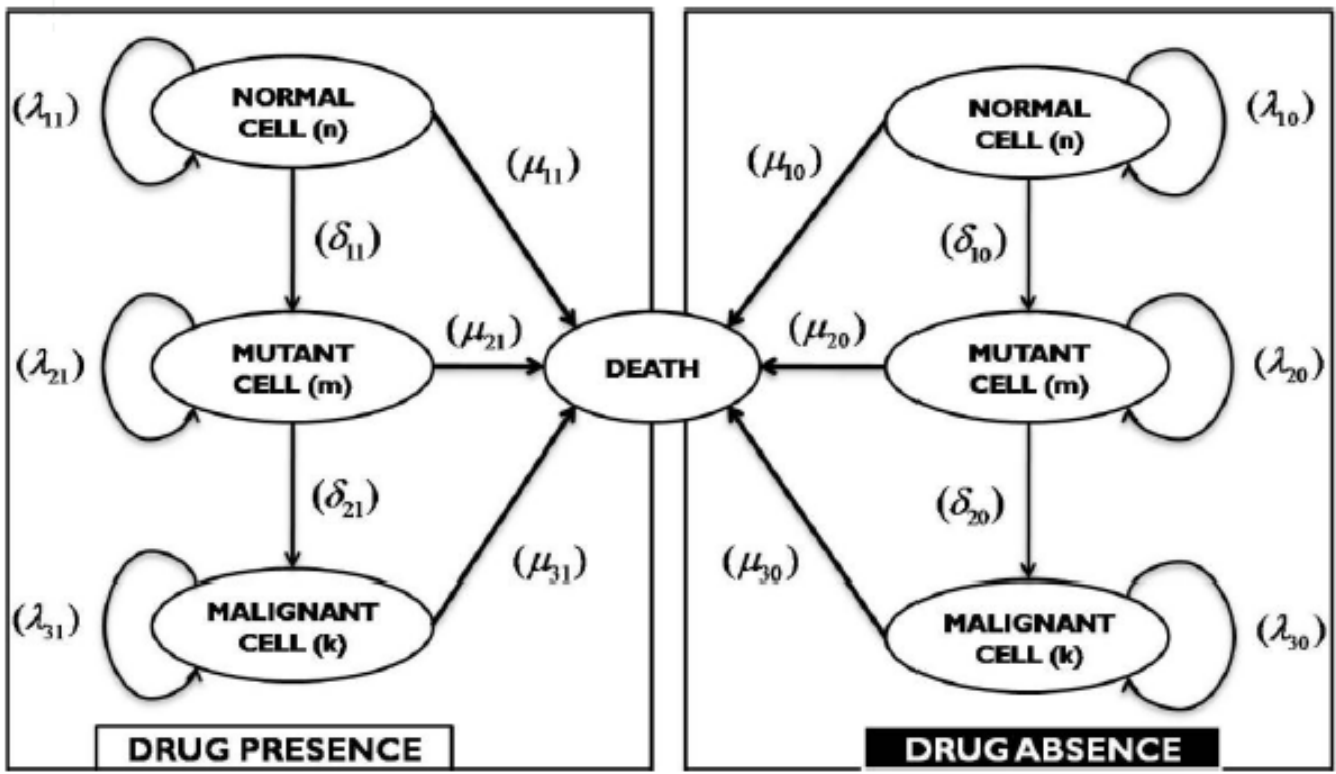

Figure 1: Schematic Diagram for Cancer Growth Processes during Chemotherapy

\section{Stochastic Model for Cancer Growth during Chemotherapy}

A Stochastic model for three stage cancer cell growth in chemotherapy is developed with the following assumptions. Let the events occurred in non-overlapping intervals of time are statistically independent. Let $\Delta \mathrm{t}$ be an infinitesimal interval of time. Let there be ' $\mathrm{n}$ ' normal cells, ' $\mathrm{m}$ ' mutant cells, ' $\mathrm{k}$ ' malignant cells initially at time't'. Let $a, b, c, d, e, f, g, h$ assuming 0 and 1 when the patient is in drug presence and absence respectively.

Let $\lambda_{i j}$ be the rate of growths; $\mu_{i j}$ be the rate of death of cells; $\delta_{k j}$ be the rate of transformation of cells from $\mathrm{k}$ to $\mathrm{k}+1$ stage. where, ' $\mathrm{I}$ ' be the stage of cells, $\mathrm{i}=1,2,3$ for normal, mutant, malignant cells respectively; ' $j$ ' be the state of drug, $j=0,1$ (absence, presence); ' $k$ ' be the transformation of cells $\mathrm{k}$ to $\mathrm{k}+1$ stage, $\mathrm{k}=1,2$. All the parameters follow poisson processes and, let postulates of the model are.

Let $\{\mathrm{N}(\mathrm{t}), \mathrm{t} \geq 0\},\{\mathrm{M}(\mathrm{t}), \mathrm{t} \geq 0\},\{\mathrm{K}(\mathrm{t}), \mathrm{t} \geq 0\}$ be individual stochastic processes of normal cell, mutant cell and malignant cell. Such that, $P\{\mathrm{~N}(\mathrm{t})=\mathrm{n}\}=P_{n}(\mathrm{t}), P\{\mathrm{M}(\mathrm{t})=m\}=P_{m}(\mathrm{t})$, $P\{\mathrm{~K}(\mathrm{t})=k\}=P_{k}(\mathrm{t})$ and let $\left.\{\mathrm{N}(\mathrm{t}), \mathrm{M}(\mathrm{t}), \mathrm{K}(\mathrm{t}) ; \mathrm{t} \geq 0)\right\}$ be the tri-variate process such that processes will be $P\{(\mathrm{~N}(\mathrm{t}), \mathrm{M}(\mathrm{t}), \mathrm{K}(\mathrm{t}))=(n, m, k)\}=P_{n, m, k}(\mathrm{t})$. Let us define,

$$
\begin{aligned}
P_{n, u} & =P\{\mathrm{~N}(\Delta \mathrm{t})=\mathrm{u} / \mathrm{N}(\mathrm{t})=\mathrm{n}\} \\
& =n\left\{a \lambda_{11}+(1-a) \lambda_{10}\right\} \Delta t+o(\Delta \mathrm{t}) \quad ; u=n+1 \\
& =n\left\{f \mu_{11}+(1-f) \mu_{10}\right\} \Delta t+o(\Delta t) \quad ; u=n-1 \\
& =1-\left\{\mathrm{n}\left(\left\{a \lambda_{11}+(1-a) \lambda_{10}\right\}+\left\{f \mu_{11}+(1-f) \mu_{10}\right\}\right) \Delta \mathrm{t}+o(\Delta \mathrm{t})\right\} ; u=n \\
& =o(\Delta t)^{2} ; u=n \pm 2 \\
P_{\mathrm{m}, \mathrm{v}} & =P\{\mathrm{M}(\Delta \mathrm{t})=v / \mathrm{M}(\mathrm{t})=m\} \\
& =m\left\{\mathrm{~b} \lambda_{21}+(1-\mathrm{b}) \lambda_{20}\right\} \Delta t+o(\Delta \mathrm{t}) \quad ; u=m+1 \\
& =m\left\{g \mu_{21}+(1-\mathrm{g}) \mu_{20}\right\} \Delta t+o(\Delta t) \quad ; u=m-1 \\
& =1-\left\{\mathrm{m}\left(\left\{\mathrm{b} \lambda_{21}+(1-\mathrm{b}) \lambda_{20}\right\}+\left\{g \mu_{21}+(1-\mathrm{g}) \mu_{20}\right\}\right) \Delta \mathrm{t}+\mathrm{o}(\Delta \mathrm{t})\right\} ; u=m \\
& =o(\Delta t)^{2} ; u=m \pm 2
\end{aligned}
$$




$$
\begin{aligned}
& P_{\mathrm{k}, \mathrm{w}}=P\{\mathrm{~K}(\Delta \mathrm{t})=w / \mathrm{K}(\mathrm{t})=k\} \\
& =k\left\{c \lambda_{31}+(1-c) \lambda_{30}\right\} \Delta t+o(\Delta \mathrm{t}) \quad ; u=k+1 \\
& =k\left\{h \mu_{31}+(1-h) \mu_{30}\right\} \Delta t+o(\Delta t) \quad ; u=k-1 \\
& =1-\left\{\mathrm{k}\left(\left\{c \lambda_{31}+(1-c) \lambda_{30}\right\}+\left\{h \mu_{31}+(1-h) \mu_{30}\right\}\right) \Delta \mathrm{t}+\mathrm{o}(\Delta \mathrm{t})\right\} ; u=k \\
& =o(\Delta t)^{2} ; u=k \pm 2 \\
& P_{n u, m v, k w}=P\{[(\mathrm{~N}(\Delta \mathrm{t}), \mathrm{M}(\Delta \mathrm{t}), \mathrm{K}(\Delta \mathrm{t})]=(u, v, w) /[(\mathrm{N}(\Delta \mathrm{t}), \mathrm{M}(\Delta \mathrm{t}), \mathrm{K}(\Delta \mathrm{t})]=(\mathrm{n}, \mathrm{m}, \mathrm{k})\} \\
& =n\left\{\mathrm{a} \lambda_{11}+(1-a) \lambda_{10}\right\} \Delta t+o(\Delta t) \quad ; u=n+1, v=m, w=k \\
& =n\left\{\mathrm{f} \mu_{11}+(1-\mathrm{f}) \mu_{10}\right\} \Delta t+o(\Delta t) \quad ; u=n-1, v=m, w=k \\
& =m\left\{\mathrm{~b} \lambda_{21}+(1-\mathrm{b}) \lambda_{20}\right\} \Delta t+o(\Delta t) ; u=n, v=m+1, w=k \\
& =m\left\{g \mu_{21}+(1-g) \mu_{20}\right\} \Delta t+o(\Delta t) ; u=n, v=m-1, w=k \\
& =k\left\{c \lambda_{31}+(1-c) \lambda_{31}\right\} \Delta t+o(\Delta t) \quad ; u=n, v=m, w=k+1 \\
& =k\left\{h \mu_{31}+(1-h) \mu_{30}\right\} \Delta t+o(\Delta t) \quad ; u=n, v=m, w=k-1 \\
& =n\left\{d \delta_{11}+(1-d) \delta_{11}\right\} \Delta t+o(\Delta t) \quad ; u=n, v=m+1, w=k \\
& =m\left\{\mathrm{e} \delta_{21}+(1-e) \delta_{21}\right\} \Delta t+o(\Delta t) \quad ; u=n, v=m, w=k+1 \\
& =1-\left\{\left[\mathrm{n}\left(\left\{\mathrm{a} \lambda_{11}+(1-a) \lambda_{10}\right\}+\left\{\mathrm{f} \mu_{11}+(1-\mathrm{f}) \mu_{10}\right\}+\left\{d \delta_{11}+(1-d) \delta_{11}\right\}\right)\right.\right. \\
& +\mathrm{m}\left(\left\{\mathrm{b} \lambda_{21}+(1-\mathrm{b}) \lambda_{20}\right\}+\left\{g \mu_{21}+(1-g) \mu_{20}\right\}+\left\{\mathrm{e} \delta_{21}+(1-e) \delta_{21}\right\}\right) \\
& \left.\left.+\mathrm{k}\left(\left\{c \lambda_{31}+(1-c) \lambda_{31}\right\}+\left\{h \mu_{31}+(1-h) \mu_{30}\right\}\right)\right] \Delta t+o(\Delta t)\right\} \\
& ; u=n, v=m, w=k \\
& =o(\Delta t)^{2} ; u=n \pm 2, v=m \pm 2, w=k \pm 2
\end{aligned}
$$

The probability of occurrence of other than the above events during an infinitesimal interval of time $\Delta t$ is $o(\Delta t)^{2}$. Let $P_{n, m, k}(t)$ be the joint probability of existence of ' $\mathrm{n}$ ' normal cells, ' $\mathrm{m}$ ' mutant cells and ' $k$ ' malignant cells in a tumor during chemotherapy per unit time ' $t$ '. Then differentialdifference equations of the model are:

$$
\begin{aligned}
P_{n, m, k}^{\prime}(t)= & -\left[n\left(\left\{a \lambda_{11}+(1-a) \lambda_{10}\right\}+\left\{d \delta_{11}+(1-d) \delta_{10}\right\}+\left\{f \mu_{11}+(1-f) \mu_{10}\right\}\right)+m\left(\left\{b \lambda_{21}\right.\right.\right. \\
& \left.\left.+(1-b) \lambda_{20}\right\}+\left\{e \delta_{21}+(1-e) \delta_{20}\right\}+\left\{g \mu_{21}+(1-g) \mu_{20}\right\}\right)+k\left(\left\{c \lambda_{31}+(1-c) \lambda_{30}\right\}\right. \\
& \left.\left.+\left\{h \mu_{31}+(1-h) \mu_{30}\right\}\right)\right] P_{n, m, k}(t)+\left[(n-1) \cdot\left\{a \lambda_{11}+(1-a) \lambda_{10}\right\}\right] P_{n-1, m, k}(t) \\
& +\left[(n+1) \cdot\left\{f \mu_{11}+(1-f) \mu_{10}\right\}\right] P_{n+1, m, k}(t)+\left[(m-1) \cdot\left\{b \lambda_{21}+(1-b) \lambda_{20}\right\}\right] P_{n, m-1, k}(t) \\
& +\left[(m+1) \cdot\left\{g \mu_{21}+(1-g) \mu_{20}\right\}\right] P_{n, m+1, k}(t)+\left[(k-1) \cdot\left\{c \lambda_{31}+(1-c) \lambda_{30}\right\}\right] P_{n, m, k-1}(t) \\
& +\left[(k+1) \cdot\left\{h \mu_{31}+(1-h) \mu_{30}\right\}\right] P_{n, m, k+1}(t)+\left[(n+1) \cdot\left\{d \delta_{11}+(1-d) \delta_{10}\right\}\right] P_{n+1, m-1, k}(t) \\
& +\left[(m+1) \cdot\left\{e \delta_{21}+(1-e) \delta_{20}\right\}\right] P_{n, m+1, k-1}(t)
\end{aligned}
$$

For $\mathrm{n}, \mathrm{m}, \mathrm{k} \geq 1$

$$
\begin{aligned}
P_{1,0,0}^{\prime}(t)=- & \left\{f \mu_{11}+(1-f) \mu_{10}\right\} P_{1,0,0}(t)+2\left\{f \mu_{11}+(1-f) \mu_{10}\right\} P_{2,0,0}(t) \\
& +\left\{g \mu_{21}+(1-g) \mu_{20}\right\} P_{1,1,0}(t)+\left\{h \mu_{31}+(1-h) \mu_{30}\right\} P_{1,0,1}(t) \\
P_{0,1,0}^{\prime}(t)=- & \left\{g \mu_{21}+(1-g) \mu_{20}\right\} P_{0,1,0}(t)+2\left\{g \mu_{21}+(1-g) \mu_{20}\right\} P_{0,2,0}(t) \\
& +\left\{f \mu_{11}+(1-f) \mu_{10}\right\} P_{1,1,0}(t)+\left\{h \mu_{31}+(1-h) \mu_{30}\right\} P_{0,1,1}(t) \\
P_{0,0,1}^{\prime}(t)=- & \left\{h \mu_{31}+(1-h) \mu_{30}\right\} P_{0,0,1}(t)+2\left\{h \mu_{31}+(1-h) \mu_{30}\right\} P_{0,0,2}(t) \\
& +\left\{g \mu_{21}+(1-g) \mu_{20}\right\} P_{0,1,1}(t)+\left\{f \mu_{11}+(1-f) \mu_{10}\right\} P_{1,0,1}(t)
\end{aligned}
$$




$$
\begin{aligned}
P_{1,1,0}^{\prime}(t)= & -\left(\left\{f \mu_{11}+(1-f) \mu_{10}\right\}+\left\{g \mu_{21}+(1-g) \mu_{20}\right\}\right) P_{1,1,0}(t)+2\left\{g \mu_{21}+(1-g) \mu_{20}\right\} P_{1,2,0}(t) \\
& +2\left\{f \mu_{11}+(1-f) \mu_{10}\right\} P_{2,1,0}(t)+\left\{h \mu_{31}+(1-h) \mu_{30}\right\} P_{1,1,1}(t)+2\left\{d \delta_{11}+(1-d) \delta_{10}\right\} P_{2,0,0}(t) \\
P_{1,0,1}^{\prime}(t)=- & \left(\left\{f \mu_{11}+(1-f) \mu_{10}\right\}+\left\{h \mu_{31}+(1-h) \mu_{30}\right\}\right) P_{1,0,1}(t)+\left\{g \mu_{21}+(1-g) \mu_{20}\right\} P_{1,1,1}(t) \\
& +2\left\{f \mu_{11}+(1-f) \mu_{10}\right\} P_{2,0,1}(t)+2\left\{h \mu_{31}+(1-h) \mu_{30}\right\} P_{1,0,2}(t)+\left\{e \delta_{21}+(1-e) \delta_{20}\right\} P_{1,1,0}(t) \\
P_{0,1,1}^{\prime}(t)=- & \left(\left\{g \mu_{21}+(1-g) \mu_{20}\right\}+\left\{h \mu_{31}+(1-h) \mu_{30}\right\}\right) P_{0,1,1}(t)+\left\{f \mu_{11}+(1-f) \mu_{10}\right\} P_{1,1,1}(t) \\
+ & 2\left\{g \mu_{21}+(1-g) \mu_{20}\right\} P_{0,2,1}(t)+2\left\{h \mu_{31}+(1-h) \mu_{30}\right\} P_{0,1,2}(t)+2\left\{e \delta_{21}+(1-e) \delta_{20}\right\} P_{0,2,0}(t) \\
P_{0,0,0}^{\prime}(t)= & \left\{h \mu_{31}+(1-h) \mu_{30}\right\} P_{0,0,1}(t)+\left\{g \mu_{21}+(1-g) \mu_{20}\right\} P_{0,1,0}(t) \\
& +\left\{f \mu_{11}+(1-f) \mu_{10}\right\} P_{1,0,0}(t)
\end{aligned}
$$

With the initial condition

$p_{N_{0}, M_{0}, K_{0}}(t)=1, p_{i, j, l}(0)=0 \quad \forall i \neq N_{0}, j \neq M_{0}, l \neq K_{0}$

Where $N_{0}$ normal cells, $M_{0}$ mutant cells and $K_{0}$ malignant cells in the tumor under chemotherapy. Let $P(x, y, z ; t)$ be the joint probability generating function of $p_{n, m, k}(t)$;

Where

$$
P(x, y, z ; t)=\sum_{k=0}^{\infty} \sum_{m=0}^{\infty} \sum_{n=0}^{\infty} x^{n} y^{m} z^{k} p_{n, m, k}(t)
$$

Multiplying the equations (2.1) to (2.8) with $x^{n} y^{m} z^{k}$ and summing overall $\mathrm{n}, \mathrm{m}$ and $\mathrm{k}$, we obtain

$$
\begin{aligned}
\sum_{k=0}^{\infty} \sum_{m=0}^{\infty} \sum_{n=0}^{\infty} x^{n} y^{m} z^{k} P_{n, m, k}^{\prime}(t)= & \sum_{k=0}^{\infty} \sum_{m=0}^{\infty} \sum_{n=0}^{\infty}-\left[n \left(\left\{a \lambda_{11}+(1-a) \lambda_{10}\right\}+\left\{d \delta_{11}+(1-d) \delta_{10}\right\}+\left\{f \mu_{11}\right.\right.\right. \\
& \left.\left.+(1-f) \mu_{10}\right\}\right] x^{n} y^{m} z^{k} P_{n, m, k}(t)+m\left(\left\{b \lambda_{21}+(1-b) \lambda_{20}\right\}+\left\{e \delta_{21}\right.\right. \\
& \left.\left.+(1-e) \delta_{20}\right\}+\left\{g \mu_{21}+(1-g) \mu_{20}\right\}\right)+k\left(\left\{c \lambda_{31}+(1-c) \lambda_{30}\right\}\right. \\
& \left.\left.+\left\{h \mu_{31}+(1-h) \mu_{30}\right\}\right)\right] x^{n} y^{m} z^{k} P_{n, m, k}(t)+\sum_{k=0}^{\infty} \sum_{m=0}^{\infty} \sum_{n=0}^{\infty}\left[(n-1) .\left\{a \lambda_{11}\right.\right. \\
& \left.\left.+(1-a) \lambda_{10}\right\}\right] x^{n} y^{m} z^{k} P_{n-1, m, k}(t)+\sum_{k=0}^{\infty} \sum_{m=0}^{\infty} \sum_{n=0}^{\infty}\left[(n+1) .\left\{f \mu_{11}\right.\right. \\
& \left.\left.+(1-f) \mu_{10}\right\}\right] x^{n} y^{m} z^{k} P_{n+1, m, k}(t)+\sum_{k=0}^{\infty} \sum_{m=0}^{\infty} \sum_{n=0}^{\infty}\left[( m - 1 ) \cdot \left\{b \lambda_{21}\right.\right. \\
& \left.\left.+(1-b) \lambda_{20}\right\}\right] x^{n} y^{m} z^{k} P_{n, m-1, k}(t)+\sum_{k=0}^{\infty} \sum_{m=0}^{\infty} \sum_{n=0}^{\infty}\left[(m+1) .\left\{g \mu_{21}\right.\right. \\
& \left.\left.+(1-g) \mu_{20}\right\}\right] x^{n} y^{m} z^{k} P_{n, m+1, k}(t)+\sum_{k=0}^{\infty} \sum_{m=0}^{\infty} \sum_{n=0}^{\infty}\left[(k-1) .\left\{c \lambda_{31}\right.\right. \\
& \left.\left.+(1-c) \lambda_{30}\right\}\right] x^{n} y^{m} z^{k} P_{n, m, k-1}(t)+\sum_{k=0}^{\infty} \sum_{m=0}^{\infty} \sum_{n=0}^{\infty}\left[(k+1) .\left\{h \mu_{31}\right.\right. \\
& \left.\left.+(1-h) \mu_{30}\right\}\right] x^{n} y^{m} z^{k} P_{n, m, k+1}(t)+\sum_{k=0}^{\infty} \sum_{m=0}^{\infty} \sum_{n=0}^{\infty}\left[(n+1) .\left\{d \delta_{11}\right.\right. \\
& \left.\left.+(1-e) \delta_{20}\right\}\right] x^{n} y^{m} z^{k} P_{n, m+1, k-1}(t) \\
& \left.\left.+(1-d) \delta_{10}\right\}\right] x^{n} y^{m} z^{k} P_{n+1, m-1, k}(t)+\sum_{k=0}^{\infty} \sum_{m=0}^{\infty} \sum_{n=0}^{\infty}\left[(m+1) .\left\{e \delta_{21}\right.\right.
\end{aligned}
$$


Simplifying and rearranging the terms in the equation (2.10) we get,

$$
\begin{aligned}
\frac{\partial}{\partial t} p(x, y, z: t)= & -\left\{\left\{a \lambda_{11}+(1-a) \lambda_{10}\right\}+\left\{d \delta_{11}+(1-d) \delta_{10}\right\}+\left\{f \mu_{11}+(1-f) \mu_{10}\right\}\right\} x \\
& \left.+\left\{a \lambda_{11}+(1-a) \lambda_{10}\right\} x^{2}+\left\{f \mu_{11}+(1-f) \mu_{10}\right\}+\left\{d \delta_{11}+(1-d) \delta_{10}\right\} y\right] \\
& \frac{\partial}{\partial x} p(x, y, z ; t)+\left[-\left\{\left\{b \lambda_{21}+(1-b) \lambda_{20}\right\}+\left\{e \delta_{21}+(1-e) \delta_{20}\right\}+\left\{g \mu_{21}\right.\right.\right. \\
& \left.\left.+(1-g) \mu_{20}\right\}\right\} y+\left\{b \lambda_{21}+(1-b) \lambda_{20}\right\} y^{2}+\left\{g \mu_{21}+(1-g) \mu_{20}\right\}+\left\{e \delta_{21}\right. \\
& \left.\left.+(1-e) \delta_{20}\right\} z\right] \frac{\partial}{\partial y} p(x, y, z ; t)+\left[-\left\{\left\{c \lambda_{31}+(1-c) \lambda_{30}\right\}+\left\{h \mu_{31}+(1\right.\right.\right. \\
& \left.\left.\left.-h) \mu_{30}\right\}\right\} z+\left\{c \lambda_{31}+(1-c) \lambda_{30}\right\} z^{2}+\left\{h \mu_{31}+(1-h) \mu_{30}\right\}\right) \frac{\partial}{\partial z} p(x, y, z ; t)
\end{aligned}
$$

We can obtain the characteristics of the model by using the joint cumulant generating function of $p_{n, m, k}(t)$. Taking $x=e^{u}, y=e^{v}, z=e^{w}$ and denoting $c(u, v, w ; t)$ as the joint cumulant generating function of $p_{n, m, k}(t)$., equation. (2.11) becomes

$$
\begin{aligned}
\frac{\partial}{\partial t} c(x, y, z: t)= & {\left[-\left\{\left\{a \lambda_{11}+(1-a) \lambda_{10}\right\}+\left\{d \delta_{11}+(1-d) \delta_{10}\right\}+\left\{f \mu_{11}+(1-f) \mu_{10}\right\}\right\}+\left\{a \lambda_{11}\right.\right.} \\
& \left.\left.+(1-a) \lambda_{10}\right\} e^{u}+\left\{f \mu_{11}+(1-f) \mu_{10}\right\} e^{-u}+\left\{d \delta_{11}+(1-d) \delta_{10}\right\} e^{v-u}\right] \frac{\partial}{\partial u} c(x, y, z ; t) \\
& +\left[-\left\{\left\{b \lambda_{21}+(1-b) \lambda_{20}\right\}+\left\{e \delta_{21}+(1-e) \delta_{20}\right\}+\left\{g \mu_{21}+(1-g) \mu_{20}\right\}\right\}+\left\{b \lambda_{21}\right.\right. \\
& \left.\left.+(1-b) \lambda_{20}\right\} e^{v}+\left\{g \mu_{21}+(1-g) \mu_{20}\right\} e^{-v}+\left\{e \delta_{21}+(1-e) \delta_{20}\right\} e^{w-v}\right] \frac{\partial}{\partial v} c(x, y, z ; t) \\
& +\left[-\left\{\left\{c \lambda_{31}+(1-c) \lambda_{30}\right\}+\left\{h \mu_{31}+(1-h) \mu_{30}\right\}\right\}+\left\{c \lambda_{31}+(1-c) \lambda_{30}\right\} e^{w}+\left\{h \mu_{31}\right.\right. \\
& \left.\left.+(1-h) \mu_{30}\right\} e^{-w}\right) \frac{\partial}{\partial w} c(x, y, z ; t)
\end{aligned}
$$

\section{Differential Equations and Statistical Measures}

Let $m_{i, j, l}(t)$ denote the moments of order $(i, j, l)$ of normal cells, mutant cells, malignant cells at time ' $\mathrm{t}$ '.

Then the differential equation governing $m_{i, j, l}(t)$ are obtain as

$$
\begin{aligned}
\frac{\partial}{\partial t} m_{1,0,0}(t)= & \left(\left\{a \lambda_{11}+(1-a) \lambda_{10}\right\}-\left\{f \mu_{11}+(1-f) \mu_{10}\right\}-\left\{e \delta_{21}+(1-e) \delta_{20}\right\}\right) m_{1,0,0}(t) \\
\frac{\partial}{\partial t} m_{0,1,0}(t)= & \left\{d \delta_{11}+(1-d) \delta_{10}\right\} m_{1,0,0}(t)+\left(\left\{b \lambda_{21}+(1-b) \lambda_{20}\right\}-\left\{g \mu_{21}+(1-g) \mu_{20}\right\}\right. \\
& \left.-\left\{e \delta_{21}+(1-e) \delta_{20}\right\}\right) m_{0,1,0}(t) \\
\frac{\partial}{\partial t} m_{0,0,1}(t)= & \left\{e \delta_{21}+(1-e) \delta_{20}\right\} m_{0,1,0}(t)+\left(\left\{c \lambda_{31}+(1-c) \lambda_{30}\right\}-\left\{h \mu_{31}+(1-h) \mu_{30}\right\}\right) m_{0,0,1}(t) \\
\frac{\partial}{\partial t} m_{1,1,0}(t)= & -\left\{d \delta_{11}+(1-d) \delta_{10}\right\} m_{1,0,0}(t)+\left\{d \delta_{11}+(1-d) \delta_{10}\right\} m_{2,0,0}(t)+\left(\left\{a \lambda_{11}+(1-a) \lambda_{10}\right\}\right. \\
& \left.-\left\{f \mu_{11}+(1-f) \mu_{10}\right\}-\left\{d \delta_{11}+(1-d) \delta_{10}\right\}\right) m_{1,1,0}(t)+\left(\left\{b \lambda_{21}+(1-b) \lambda_{20}\right\}-\left\{g \mu_{21}\right.\right. \\
& \left.\left.+(1-g) \mu_{20}\right\}-\left\{e \delta_{21}+(1-e) \delta_{20}\right\}\right) m_{1,1,0}(t)
\end{aligned}
$$




$$
\begin{aligned}
\frac{\partial}{\partial t} m_{1,0,1}(t)= & \left(\left\{a \lambda_{11}+(1-a) \lambda_{10}\right\}-\left\{f \mu_{11}+(1-f) \mu_{10}\right\}-\left\{d \delta_{11}+(1-d) \delta_{10}\right\}\right) m_{1,0,1}(t) \\
& +\left(\left\{c \lambda_{31}+(1-c) \lambda_{30}\right\}-\left\{h \mu_{31}+(1-h) \mu_{30}\right\}\right) m_{1,0,1}(t)+\left\{e \delta_{21}+(1-e) \delta_{20}\right\} m_{1,1,0}(t) \\
\frac{\partial}{\partial t} m_{0,1,1}(t)= & \left\{d \delta_{11}+(1-d) \delta_{10}\right\} m_{1,0,1}(t)-\left\{e \delta_{21}+(1-e) \delta_{20}\right\} m_{0,1,0}(t)+\left\{e \delta_{21}+(1-e) \delta_{20}\right\} m_{0,2,0}(t) \\
& +\left(\left\{b \lambda_{21}+(1-b) \lambda_{20}\right\}-\left\{g \mu_{21}+(1-g) \mu_{20}\right\}-\left\{e \delta_{21}+(1-e) \delta_{20}\right\}\right) m_{0,1,1}(t)+\left(\left\{c \lambda_{31}\right.\right. \\
& \left.\left.+(1-c) \lambda_{30}\right\}-\left\{h \mu_{31}+(1-h) \mu_{30}\right\}\right) m_{0,1,1}(t) \\
\frac{\partial}{\partial t} m_{2,0,0}(t)= & \left(\left\{a \lambda_{11}+(1-a) \lambda_{10}\right\}+\left\{d \delta_{11}+(1-d) \delta_{10}\right\}+\left\{f \mu_{11}+(1-f) \mu_{10}\right\}\right) m_{1,0,0}(t) \\
& +2\left(\left\{a \lambda_{11}+(1-a) \lambda_{10}\right\}-\left\{f \mu_{11}+(1-f) \mu_{10}\right\}-\left\{d \delta_{11}+(1-d) \delta_{10}\right\}\right) m_{2,0,0}(t) \\
\frac{\partial}{\partial t} m_{0,2,0}(t)= & \left\{d \delta_{11}+(1-d) \delta_{10}\right\} m_{1,0,0}(t)+2\left\{d \delta_{11}+(1-d) \delta_{10}\right\} m_{1,1,0}(t)+\left(\left\{b \lambda_{21}+(1-b) \lambda_{20}\right\}\right. \\
& \left.+\left\{g \mu_{21}+(1-g) \mu_{20}\right\}+\left\{e \delta_{21}+(1-e) \delta_{20}\right\}\right) m_{0,1,0}(t)+2\left(\left\{b \lambda_{21}+(1-b) \lambda_{20}\right\}-\left\{g \mu_{21}\right.\right. \\
& \left.\left.+(1-g) \mu_{20}\right\}-\left\{e \delta_{21}+(1-e) \delta_{20}\right\}\right) m_{0,2,0}(t) \\
& \left.+\left\{h \mu_{31}+(1-h) \mu_{30}\right\}\right) m_{0,0,1}(t)+2\left(\left\{c \lambda_{31}+(1-c) \lambda_{30}\right\}-\left\{h \mu_{31}+(1-h) \mu_{30}\right\}\right) m_{0,0,2}(t) \\
\frac{\partial}{\partial t} m_{0,0,2}(t)= & \left\{e \delta_{21}+(1-e) \delta_{20}\right\} m_{0,1,0}(t)+2\left\{e \delta_{21}+(1-e) \delta_{20}\right\} m_{0,1,1}(t)+\left(\left\{c \lambda_{31}+(1-c) \lambda_{30}\right\}\right.
\end{aligned}
$$

Expected number of normal cells at time ' $\mathrm{t}$ ' is

$$
m_{1,0,0}(t)=N_{0} \cdot e^{A t}
$$

Expected number of mutant cells at time ' $\mathrm{t}$ ' is

$$
m_{0,1,0}(t)=\frac{\left\{d \delta_{11}+(1-d) \delta_{10}\right\} N_{0}}{(A-B)}\left[e^{A t}-e^{B t}\right]+M_{0} e^{B t}
$$

Expected number of malignant cells during time ' $\mathrm{t}$ ' is

$m_{0,0,1}(t)=D e^{C t}\left(\frac{e^{(A-C) t}}{(A-C)}-\frac{e^{(B-C) t}}{(B-C)}\right)+\frac{\left\{e \delta_{21}+(1-e) \delta_{20}\right\} M_{0}}{(B-C)} e^{B t}+E \cdot e^{C t}$

Variance of number of normal cells at time ' $\mathrm{t}$ ' is

$$
m_{2,0,0}(t)=\frac{N_{0} H}{A}\left[e^{2 . A t}-e^{A t}\right]
$$

Variance of number of mutant cells at time ' $\mathrm{t}$ ' is

$$
m_{0,2,0}(t)=D_{0} \cdot e^{A t}+E_{0} \cdot e^{B t}+F_{0} \cdot e^{2 A t}-G_{0} \cdot e^{(A+B) t}+H_{0} \cdot e^{2 B t}
$$

Variance of number of malignant cells at time ' $\mathrm{t}$ ' is

$$
\begin{aligned}
m_{0,0,2}(t)= & \frac{R_{1} e^{A t}}{(A-2 C)}+\frac{R_{2} e^{B t}}{(B-2 C)}+2 \delta_{2}\left\{\frac{A_{2} e^{2 A t}}{2(A-C)}+\frac{A_{4} e^{2 B t}}{2(B-C)}+\frac{A_{5} e^{(B-C) t}}{(B-3 C)}-\frac{A_{6} e^{(A+C) t}}{(A-C)}\right. \\
& \left.-\frac{\delta_{2} G_{0} e^{(A+B) t}}{(A+B-2 C)}-\frac{J_{0} e^{(B+C) t}}{(B-C)}\right\}-\frac{P E e^{C t}}{C}-S_{0} \cdot e^{2 c t}
\end{aligned}
$$


Covariance of number of normal and mutant cells at time ' $\mathrm{t}$ ' is

$$
m_{1,1,0}(t)=\frac{\left\{d \delta_{11}+(1-d) \delta_{10}\right\} N_{0} H}{A(A-B)} e^{2 \cdot A t}+\frac{\left\{d \delta_{11}+(1-d) \delta_{10}\right\} N_{0}}{B}\left(1+\frac{H}{A}\right) e^{A t}-I \cdot e^{(A+B) t}
$$

Covariance of number of mutant and malignant cell at time ' $\mathrm{t}$ ' is

$$
\begin{aligned}
m_{0,1,1}(t)= & A_{1} \cdot e^{2 A t}+A_{2} \cdot e^{A t}-A_{3} \cdot e^{B t}+A_{4} \cdot e^{2 B t}+A_{5} \cdot e^{(B-C) t}-A_{6} \cdot e^{(A+C) t} \\
& -\delta_{2} G_{0} \cdot e^{(A+B) t}-J_{0} \cdot e^{(B+C) t}
\end{aligned}
$$

Covariance of number of normal and malignant cells at time ' $\mathrm{t}$ ' is

$$
m_{1,0,1}(t)=A_{0} \cdot e^{2 A t}-B_{0} \cdot e^{A t}-C_{0} \cdot e^{(B-C) t}+I_{0} \cdot e^{(A+C) t}
$$

where

$$
\begin{aligned}
& A=\left(\left\{a \lambda_{11}+(1-a) \lambda_{10}\right\}-\left\{f \mu_{11}+(1-f) \mu_{10}\right\}-\left\{d \delta_{11}+(1-d) \delta_{10}\right\}\right) ; \\
& B=\left(\left\{b \lambda_{21}+(1-b) \lambda_{20}\right\}-\left\{g \mu_{21}+(1-g) \mu_{20}\right\}-\left\{e \delta_{21}+(1-e) \delta_{20}\right\}\right) ; \\
& C=\left(\left\{c \lambda_{31}+(1-c) \lambda_{30}\right\}-\left\{h \mu_{31}+(1-h) \mu_{30}\right\}\right) ; D=\frac{\left\{d \delta_{11}+(1-d) \delta_{10}\right\}\left\{e \delta_{21}+(1-e) \delta_{20}\right\}}{A-B} N_{0} ; \\
& E=K_{0} \frac{D(B-A)}{(A-C)(B-C)}+\frac{M_{0}}{(B-C)}\left\{e \delta_{21}+(1-e) \delta_{20}\right\} ; \\
& H=\left(\left\{a \lambda_{11}+(1-a) \lambda_{10}\right\}+\left\{f \mu_{11}+(1-f) \mu_{10}\right\}+\left\{d \delta_{11}+(1-d) \delta_{10}\right\}\right) ; \\
& I=\frac{\left\{d \delta_{11}+(1-d) \delta_{10}\right\} N_{0} H}{A(A-B)}+\frac{\left\{d \delta_{11}+(1-d) \delta_{10}\right\} N_{0}}{B}\left(1+\frac{H}{A}\right) ; \\
& J=\left(\left\{b \lambda_{21}+(1-b) \lambda_{20}\right\}+\left\{g \mu_{21}+(1-g) \mu_{20}\right\}+\left\{e \delta_{21}+(1-e) \delta_{20}\right\}\right) ; \\
& D_{0}=\frac{\left\{d \delta_{11}+(1-d) \delta_{10}\right\} N_{0}}{(A-2 B)}+\frac{2\left\{d \delta_{11}+(1-d) \delta_{10}\right\}^{2} N_{0}}{B(A-2 B)}+\frac{J\left\{d \delta_{11}+(1-d) \delta_{10}\right\} N_{0}}{(A-B)(A-2 B)} ; \\
& E_{0}=
\end{aligned}
$$$$
A_{2}=\frac{\left\{e \delta_{21}+(1-e) \delta_{20}\right\} D_{0}-\left\{d \delta_{11}+(1-d) \delta_{10}\right\} B_{0}-\frac{\left\{d \delta_{11}+(1-d) \delta_{10}\right\} N_{0}}{A-B}}{A-B-C} ;
$$$$
A_{3}=\frac{\left\{e \delta_{21}+(1-e) \delta_{20}\right\} E_{0}-M_{0}+\frac{\left\{d \delta_{11}+(1-d) \delta_{10}\right\} N_{0}}{A-B}}{C} \quad ; A_{4}=\frac{\left\{d \delta_{11}+(1-d) \delta_{10}\right\} H_{0}}{B-C}
$$$$
A_{5}=\frac{\left\{d \delta_{11}+(1-d) \delta_{10}\right\} C_{0}}{2 C} \quad ; A_{6}=\frac{\left\{d \delta_{11}+(1-d) \delta_{10}\right\} I_{0}}{A-B}
$$$$
; P=\left(\left\{c \lambda_{31}+(1-c) \lambda_{30}\right\}+\left\{h \mu_{31}+(1-h) \mu_{30}\right\}\right) ;
$$ 


$$
\begin{aligned}
& R_{1}=\frac{\left\{d \delta_{11}+(1-d) \delta_{10}\right\}\left\{e \delta_{21}+(1-e) \delta_{20}\right\} N_{0}}{A-B}+2 A_{2}\left\{e \delta_{21}+(1-e) \delta_{20}\right\}+\frac{P D}{(A-C)} \\
& R_{2}=\delta_{2} M_{0}-\frac{\left\{d \delta_{11}+(1-d) \delta_{10}\right\}\left\{e \delta_{21}+(1-e) \delta_{20}\right\} M_{0} N_{0}}{(A-B)} \\
& +\frac{P\left\{e \delta_{21}+(1-e) \delta_{20}\right\} M_{0}}{(B-C)}-\frac{P D}{(B-C)} \\
& S_{0}=\frac{R_{1}}{(A-2 C)}+\frac{R_{2}}{(B-2 C)}+2\left\{e \delta_{21}+(1-e) \delta_{20}\right\}\left\{\frac{A_{2}}{2(A-C)}+\frac{A_{4}}{2(B-C)}+\frac{A_{5}}{(B-3 C)}\right. \\
& \left.-\frac{A_{6}}{(A-C)}-\frac{\left\{e \delta_{21}+(1-e) \delta_{20}\right\} G_{0}}{(A+B-2 C)}-\frac{J_{0}}{(B-C)}\right\}-\frac{P E}{C} \\
& I_{0}=\frac{\left\{d \delta_{11}+(1-d) \delta_{10}\right\} N_{0}}{B C}\left(1+\frac{H}{A}\right)+\frac{I}{(B-C)}-\frac{\left\{d \delta_{11}+(1-d) \delta_{10}\right\} N_{0} H}{A(A-B)(A-C)} \\
& J_{0}=\frac{\left\{d \delta_{11}+(1-d) \delta_{10}\right\} A_{0}+\left\{e \delta_{21}+(1-e) \delta_{20}\right\} F_{0}}{(2 A-B-C)} \\
& +\frac{\left\{e \delta_{21}+(1-e) \delta_{20}\right\} D_{0}-\left\{d \delta_{11}+(1-d) \delta_{10}\right\} B_{0}-\left(\frac{\left\{d \delta_{11}+(1-d) \delta_{10}\right\} N_{0}}{(A-B)}\right)}{} \\
& (A-B-C) \\
& -\frac{\left\{e \delta_{21}+(1-e) \delta_{20}\right\}\left(E_{0}-M_{0}+\frac{\left\{d \delta_{11}+(1-d) \delta_{10}\right\} N_{0}}{(A-B)}\right)}{C} \\
& \text { C } \\
& +\frac{\left\{d \delta_{11}+(1-d) \delta_{10}\right\} N_{0}}{(B-C)}+\frac{\left\{d \delta_{11}+(1-d) \delta_{10}\right\} C_{0}}{2 C}-\frac{\left\{d \delta_{11}+(1-d) \delta_{10}\right\} I_{0}}{(A-B)} \\
& -\left\{e \delta_{21}+(1-e) \delta_{20}\right\} G_{0}
\end{aligned}
$$

\section{Numerical Illustration and sensitivity analysis}

In order to understand the model behavior on more detailed way, a simulated data set based were obtained. From equations (3.10), (3.11), (3.12), (3.13), (3.14), (3.15), (3.16), (3.17) and (3.18) the values of $m_{1,0,0}(t), m_{0,1,0}(t), m_{0,0,1}(t), m_{1,1,0}(t), m_{1,0,1}(t), m_{0,1,1}(t), m_{2,0,0}(t), m_{0,2,0}(t) \quad$ and $m_{0,0,2}(t)$ are computed and presented in tables (4.1), (4.2), (4.3) and (4.4).

The changing patterns of statistical measures with respect to the study parameters are presented in table 4.1 and the following findings are observed.

- $\mathrm{m}_{100}, \mathrm{~m}_{010}$, and $\mathrm{m}_{001}, \mathrm{~m}_{110}, \mathrm{~m}_{101}$ and $\mathrm{m}_{011}, \mathrm{~m}_{200}, \mathrm{~m}_{020}$ and $\mathrm{m}_{002}$ are increasing with $\lambda_{11}$ when all other parameters are constants.

- $\mathrm{m}_{100}$ is invariant, $\mathrm{m}_{010}$ and $\mathrm{m}_{001}$ are increasing; $\mathrm{m}_{110}, \mathrm{~m}_{101}$ and $\mathrm{m}_{011}$ are increasing; $\mathrm{m}_{200}$ is invariant, $\mathrm{m}_{020}$ and $\mathrm{m}_{002}$ are increasing with $\lambda_{21}$ when all other parameters are constants.

- $\mathrm{m}_{100}, \mathrm{~m}_{010}$ are invariant, $\mathrm{m}_{001}$ is increasing; $\mathrm{m}_{110}$ is invariant, $\mathrm{m}_{101}$ is increasing function and $\mathrm{m}_{011}$ is decreasing function; $\mathrm{m}_{200}, \mathrm{~m}_{020}$ are invariant and $\mathrm{m}_{002}$ is decreasing with $\lambda 31$ when all other parameters are constants.

- $\mathrm{m}_{100}, \mathrm{~m}_{010}$ are decreasing and $\mathrm{m}_{001}$ is increasing; $\mathrm{m}_{110}, \mathrm{~m}_{101}$ are decreasing and $\mathrm{m}_{011}$ is increasing; $\mathrm{m}_{200}, \mathrm{~m}_{002}$ are decreasing and $\mathrm{m}_{020}$ is increasing with $\delta_{11}$ when all other parameters are constants. 
- $\mathrm{m}_{100}$ is invariant, $\mathrm{m}_{010}$ is decreasing and $\mathrm{m}_{001}$ is increasing; $\mathrm{m}_{110}, \mathrm{~m}_{101}$ and $\mathrm{m}_{011}$ are decreasing; $\mathrm{m}_{200}$ is invariant, $\mathrm{m}_{020}$ and $\mathrm{m}_{002}$ are decreasing with $\delta_{21}$ when all other parameters are constants.

- $\quad \mathrm{m}_{100}, \mathrm{~m}_{010}$, and $\mathrm{m}_{001}$ are increasing; $\mathrm{m}_{110}, \mathrm{~m}_{101}$ and $\mathrm{m}_{011}$ are increasing; $\mathrm{m}_{200}, \mathrm{~m}_{020}$, and $\mathrm{m}_{002}$ are increasing with time $t$ when all other parameters are constants.

The changing patterns of statistical measures with respect to the study parameters are presented in table 4.2 and the following findings are observed.

- $\mathrm{m}_{100}, \mathrm{~m}_{010}$ and $\mathrm{m}_{001}$ are decreasing; $\mathrm{m}_{110}, \mathrm{~m}_{101}$ and $\mathrm{m}_{011}$ are decreasing; $\mathrm{m}_{200}, \mathrm{~m}_{020}$ and $\mathrm{m}_{002}$ are decreasing with $\mu_{11}$ when all other parameters are constants.

- $\mathrm{m}_{100}$ is invariant, $\mathrm{m}_{010}$ and $\mathrm{m}_{001}$ are decreasing; $\mathrm{m}_{110}, \mathrm{~m}_{101}$ and $\mathrm{m}_{011}$ are decreasing; $\mathrm{m}_{200}$ is invariant, $\mathrm{m}_{020}$ and $\mathrm{m}_{002}$ are decreasing with $\mu_{21}$ when all other parameters are constants.

- $\mathrm{m}_{100}, \mathrm{~m}_{010}$ are invariant and $\mathrm{m}_{001}$ is decreasing; $\mathrm{m}_{110}$ is invariant, $\mathrm{m}_{101}$ is decreasing and $\mathrm{m}_{011}$ is increasing; $\mathrm{m}_{200}, \mathrm{~m}_{020}$ are invariant and $\mathrm{m}_{002}$ is increasing with $\mu_{31}$ when all other parameters are constants.

- $\mathrm{m}_{100}, \mathrm{~m}_{010}$ and $\mathrm{m}_{001}$ are increasing; $\mathrm{m}_{110}, \mathrm{~m}_{101}$ and $\mathrm{m}_{011}$ are increasing; $\mathrm{m}_{200}, \mathrm{~m}_{020}$ and $\mathrm{m}_{002}$ are increasing with $\mathrm{N}_{0}$ when all other parameters are constants.

- $\mathrm{m}_{100}$ is invariant, $\mathrm{m}_{010}$ and $\mathrm{m}_{001}$ are increasing; $\mathrm{m}_{110}, \mathrm{~m}_{101}$, and $\mathrm{m}_{011}$ are invariant; $\mathrm{m}_{200}, \mathrm{~m}_{020}$ are invariant and $\mathrm{m}_{002}$ is decreasing with $\mathrm{M}_{0}$ when all other parameters are constants.

- $\mathrm{m}_{100}, \mathrm{~m}_{010}$ are invariant and $\mathrm{m}_{001}$ is increasing; $\mathrm{m}_{110}, \mathrm{~m}_{101}$ and $\mathrm{m}_{011}$ are invariant; $\mathrm{m}_{200}, \mathrm{~m}_{020}$ and $\mathrm{m}_{002}$ are invariant with $\mathrm{K}_{0}$ when all other parameters are constants.

The changing patterns of statistical measures with respect to the study parameters are presented in table 4.3 and the following findings are observed.

- $\mathrm{m}_{100}, \mathrm{~m}_{010}$ and $\mathrm{m}_{001}$ are increasing; $\mathrm{m}_{110}$ is increasing, $\mathrm{m}_{101}$ and $\mathrm{m}_{011}$ are negative $\&$ increasing; $\mathrm{m}_{200}, \mathrm{~m}_{020}$ and $\mathrm{m}_{002}$ are increasing with $\lambda_{10}$ when all other parameters are constants.

- $\quad \mathrm{m}_{100}$ is invariant and $\mathrm{m}_{010}, \mathrm{~m}_{001}$ are increasing; $\mathrm{m}_{110}, \mathrm{~m}_{011}$ are decreasing and $\mathrm{m}_{101}$ is increasing; $\mathrm{m}_{200}$ is invariant, $\mathrm{m}_{020}$ is increasing and $\mathrm{m}_{002}$ is decreasing with $\lambda_{20}$ when all other parameters are constants.

- $\mathrm{m}_{100}, \mathrm{~m}_{010}$ are invariant and $\mathrm{m}_{001}$ is increasing; $\mathrm{m}_{110}$ is invariant, $\mathrm{m}_{101}$ and $\mathrm{m}_{011}$ are negative \& decreasing; $\mathrm{m}_{200}, \mathrm{~m}_{020}$ are invariant and $\mathrm{m}_{002}$ is increasing with $\lambda_{30}$ when all other parameters are constants.

- $\mathrm{m}_{100}, \mathrm{~m}_{010}$ are decreasing and $\mathrm{m}_{001}$ is increasing; $\mathrm{m}_{110}$ is decreasing, $\mathrm{m}_{101}$ and $\mathrm{m}_{011}$ are negative $\&$ increasing; $\mathrm{m}_{200}, \mathrm{~m}_{020}$ and $\mathrm{m}_{002}$ are decreasing with $\delta_{10}$ when all other parameters are constants.

- $\mathrm{m}_{100}$ is invariant, $\mathrm{m}_{010}$ is decreasing and $\mathrm{m}_{001}$ is increasing; $\mathrm{m}_{110}$ is increasing, $\mathrm{m}_{101}$ is negative $\&$ decreasing and $\mathrm{m}_{11}$ is negative \& increasing; $\mathrm{m}_{200}$ is invariant, $\mathrm{m}_{020}$ is decreasing and $\mathrm{m}_{002}$ is increasing with $\delta_{20}$ when all other parameters are constants.

- $\mathrm{m}_{100}, \mathrm{~m}_{010}$ are decreasing and $\mathrm{m}_{001}$ is increasing; $\mathrm{m}_{110}$ is decreasing, $\mathrm{m}_{101}$ and $\mathrm{m}_{011}$ are negative \& increasing; $\mathrm{m}_{200}, \mathrm{~m}_{020}$ are decreasing and $\mathrm{m}_{002}$ is increasing with time $\mathrm{t}$ when all other parameters are constants.

The changing patterns of statistical measures with respect to the study parameters are presented in table 4.3 and the following findings are observed.

- $\mathrm{m}_{100}, \mathrm{~m}_{010}$ and $\mathrm{m}_{001}$ are decreasing; $\mathrm{m}_{110}$ is decreasing, $\mathrm{m}_{101}$ is negative \& increasing function and $\mathrm{m}_{011}$ is negative and decreasing function of $\mu_{10} ; \mathrm{m}_{200}, \mathrm{~m}_{020}$ and $\mathrm{m}_{002}$ are decreasing with $\mu_{10}$ when all other parameters are constants.

- $\mathrm{m}_{100}$ is invariant, $\mathrm{m}_{010}$ and $\mathrm{m}_{001}$ are decreasing; $\mathrm{m}_{110}$ is increasing, $\mathrm{m}_{101}$ is negative \& decreasing and $\mathrm{m}_{011}$ is negative $\&$ increasing; $\mathrm{m}_{200}$ is invariant, $\mathrm{m}_{020}$ is decreasing and $\mathrm{m}_{002}$ is increasing with $\mu_{20}$ when all other parameters are constants.

- $\mathrm{m}_{100}, \mathrm{~m}_{010}$ are invariant and $\mathrm{m}_{001}$ is decreasing; $\mathrm{m}_{110}$ is invariant, $\mathrm{m}_{101}$ and $\mathrm{m}_{011}$ are negative \& increasing; $\mathrm{m}_{200}, \mathrm{~m}_{020}$ are invariant and $\mathrm{m}_{002}$ is decreasing with $\mu_{30}$ when all other parameters are constants.

- $\quad \mathrm{m}_{100}, \mathrm{~m}_{010}$ and $\mathrm{m}_{001}$ are increasing; $\mathrm{m}_{110}$ is increasing, $\mathrm{m}_{101}$ and $\mathrm{m}_{011}$ are negative \& decreasing; $\mathrm{m}_{200}, \mathrm{~m}_{020}$ and $\mathrm{m}_{002}$ are increasing with $\mathrm{N}_{0}$ when all other parameters are constants. 
- $\mathrm{m}_{100}$ is invariant, $\mathrm{m}_{010}$ and $\mathrm{m}_{001}$ are increasing; $\mathrm{m}_{110}$ is invariant, $\mathrm{m}_{101}$ is negative $\&$ invariant and $\mathrm{m}_{011}$ is decreasing; $\mathrm{m}_{200}$ is invariant and $\mathrm{m}_{020}, \mathrm{~m}_{002}$ are increasing with $\mathrm{M}_{0}$ when all other parameters are constants.

- $\quad \mathrm{m}_{100}, \mathrm{~m}_{010}$ are invariant and $\mathrm{m}_{001}$ is increasing; $\mathrm{m}_{110}$ is invariant and $\mathrm{m}_{101}, \mathrm{~m}_{011}$ are negative \& invariant; $\mathrm{m}_{200}, \mathrm{~m}_{020}$ are invariant and $\mathrm{m}_{002}$ is increasing with $\mathrm{K}_{0}$ when all other parameters are constants.

\section{Acknowledgements}

The authors are thankful to acknowledge the funding agency to extract this study as the first author is the principal investigator of a major research project work entitled " sponsored by the Scientific and Engineering Research Board (SERB), Department of Science \& Technology (DST), Govt. of India.

\section{Appendix}

Table 4.1: Values of $\mathrm{m}_{100}, \mathrm{~m}_{010}, \mathrm{~m}_{001} \mathrm{~m}_{110}, \mathrm{~m}_{101}, \mathrm{~m}_{011} \mathrm{~m}_{200}, \mathrm{~m}_{020}$, and $\mathrm{m}_{002}$ for varying values of $\lambda_{11}$, $\lambda_{21}, \lambda_{31}, \delta_{11}, \delta_{21}$ and $\mathrm{t}$.

\begin{tabular}{|c|c|c|c|c|c|c|c|c|c|c|c|c|c|c|}
\hline$\lambda_{\mu}$ & $\lambda_{21}$ & $\lambda_{31}$ & $\delta_{\mu 1}$ & $\delta_{21}$ & $t$ & $\mathbf{m}_{100}$ & $\mathbf{m}_{010}$ & $\mathbf{m}_{001}$ & $\mathbf{m}_{10}$ & $\mathbf{m}_{101}$ & $\mathbf{m}_{011}$ & $\mathbf{m}_{200}$ & $\mathbf{m}_{020}$ & $\mathbf{m}_{n 02}$ \\
\hline 4.02 & 0.5 & 1 & 1 & 2 & 1 & 6711 & 1471 & 1440 & 35790 & 9413 & 17780 & 196000 & 10560 & 61810 \\
\hline 4.04 & 0.5 & 1 & 1 & 2 & 1 & 6846 & 1494 & 1451 & 37110 & 9740 & 18050 & 203600 & 10850 & 63930 \\
\hline 4.06 & 0.5 & 1 & 1 & 2 & 1 & 6985 & 1518 & 1462 & 38480 & 10080 & 18340 & 211500 & 11140 & 66110 \\
\hline 4.08 & 0.5 & 1 & 1 & 2 & 1 & 7126 & 1542 & 1474 & 39900 & 10430 & 18620 & 219700 & 11450 & 68340 \\
\hline 4.10 & 0.5 & 1 & 1 & 2 & 1 & 7270 & 1566 & 1485 & 41380 & 10790 & 18920 & 228200 & 11770 & 70630 \\
\hline 4.12 & 0.5 & 1 & 1 & 2 & 1 & 7417 & 1590 & 1497 & 42900 & 11160 & 19220 & 237000 & 12090 & 72980 \\
\hline 4 & 0.52 & 1 & 1 & 2 & 1 & 6578 & 1455 & 1435 & 34630 & 9144 & 17740 & 188700 & 10370 & 60800 \\
\hline 4 & 0.54 & 1 & 1 & 2 & 1 & 6578 & 1462 & 1440 & 34750 & 9192 & 17980 & 188700 & 10460 & 61880 \\
\hline 4 & 0.56 & 1 & 1 & 2 & 1 & 6578 & 1469 & 1446 & 34870 & 9242 & 18220 & 188700 & 10550 & 62990 \\
\hline 4 & 0.58 & 1 & 1 & 2 & 1 & 6578 & 1475 & 1451 & 34990 & 9293 & 18470 & 188700 & 10650 & 64130 \\
\hline 4 & 0.6 & 1 & 1 & 2 & 1 & 6578 & 1482 & 1457 & 35110 & 9345 & 18720 & 188700 & 10740 & 65300 \\
\hline 4 & 0.62 & 1 & 1 & 2 & 1 & 6578 & 1489 & 1462 & 35230 & 9399 & 18980 & 188700 & 10840 & 66500 \\
\hline 4 & 0.5 & 1.02 & 1 & 2 & 1 & 6578 & 1449 & 1442 & 34520 & 9125 & 17230 & 188700 & 10280 & 56730 \\
\hline 4 & 0.5 & 1.04 & 1 & 2 & 1 & 6578 & 1449 & 1455 & 34520 & 9153 & 16990 & 188700 & 10280 & 53880 \\
\hline 4 & 0.5 & 1.06 & 1 & 2 & 1 & 6578 & 1449 & 1468 & 34520 & 9181 & 16760 & 188700 & 10280 & 51170 \\
\hline 4 & 0.5 & 1.08 & 1 & 2 & 1 & 6578 & 1449 & 1481 & 34520 & 9209 & 16560 & 188700 & 10280 & 48580 \\
\hline 4 & 0.5 & 1.10 & 1 & 2 & 1 & 6578 & 1449 & 1494 & 34520 & 9238 & 16380 & 188700 & 10280 & 46090 \\
\hline 4 & 0.5 & 1.12 & 1 & 2 & 1 & 6578 & 1449 & 1508 & 34520 & 9266 & 16220 & 188700 & 10280 & 43700 \\
\hline 4 & 0.5 & 1 & 1.1 & 2 & 1 & 5952 & 1472 & 1473 & 33030 & 8848 & 20150 & 162200 & 11080 & 65570 \\
\hline 4 & 0.5 & 1 & 1.2 & 2 & 1 & 5385 & 1484 & 1510 & 31350 & 8536 & 22900 & 139400 & 11800 & 71110 \\
\hline 4 & 0.5 & 1 & 1.3 & 2 & 1 & 4873 & 1486 & 1541 & 29550 & 8180 & 25750 & 119900 & 12440 & 76440 \\
\hline 4 & 0.5 & 1 & 1.4 & 2 & 1 & 4409 & 1481 & 1567 & 27690 & 7793 & 28730 & 103100 & 13010 & 81630 \\
\hline 4 & 0.5 & 1 & 1.5 & 2 & 1 & 3990 & 1469 & 1588 & 25830 & 7389 & 31850 & 88730 & 13510 & 86800 \\
\hline 4 & 0.5 & 1 & 1.6 & 2 & 1 & 3610 & 1451 & 1605 & 23990 & 6976 & 35150 & 76380 & 13960 & 13960 \\
\hline 4 & 0.5 & 1 & 1 & 2.1 & 1 & 6578 & 1417 & 1465 & 33940 & 8880 & 16600 & 188700 & 9882 & 58040 \\
\hline 4 & 0.5 & 1 & 1 & 2.2 & 1 & 6578 & 1386 & 1500 & 33380 & 8685 & 15770 & 188700 & 9511 & 56500 \\
\hline 4 & 0.5 & 1 & 1 & 2.3 & \begin{tabular}{|l|}
1 \\
\end{tabular} & 6578 & 1357 & 1533 & 32840 & 8509 & 15020 & 188700 & 9162 & 55130 \\
\hline 4 & 0.5 & 1 & 1 & 2.4 & \begin{tabular}{|l|}
1 \\
\end{tabular} & 6578 & 1329 & 1564 & 32310 & 8349 & 14330 & 188700 & 8834 & 53890 \\
\hline 4 & 0.5 & 1 & 1 & 2.5 & 1 & 6578 & 1302 & 1594 & 31800 & 8201 & 13700 & 188700 & 8524 & 52770 \\
\hline 4 & 0.5 & 1 & 1 & 2.6 & \begin{tabular}{|l|}
1 \\
\end{tabular} & 6578 & 1276 & 1623 & 31300 & 8063 & 13110 & 188700 & 8232 & 51770 \\
\hline 4 & 0.5 & 1 & 1 & 2 & 2 & $1.08 \mathrm{E}+05$ & $2.35 \mathrm{E}+04$ & $2.08 \mathrm{E}+04$ & $1.16 \mathrm{E}+07$ & $4.64 \mathrm{E}+06$ & $1.75 \mathrm{E}+06$ & $5.41 \mathrm{E}+07$ & $2.58 \mathrm{E}+06$ & $1.98 \mathrm{E}+07$ \\
\hline 4 & 0.5 & 1 & 1 & 2 & \begin{tabular}{|l|}
3 \\
\end{tabular} & $1.78 \mathrm{E}+06$ & $3.87 \mathrm{E}+05$ & $3.37 \mathrm{E}+05$ & $3.19 \mathrm{E}+09$ & $1.37 \mathrm{E}+09$ & $4.09 \mathrm{E}+08$ & $1.47 \mathrm{E}+10$ & $6.94 \mathrm{E}+08$ & $5.23 \mathrm{E}+09$ \\
\hline 4 & 0.5 & 1 & 1 & 2 & 4 & $2.93 \mathrm{E}+07$ & $6.36 \mathrm{E}+06$ & $5.53 \mathrm{E}+06$ & $8.64 \mathrm{E}+11$ & $3.75 \mathrm{E}+11$ & $1.09 \mathrm{E}+11$ & $3.97 \mathrm{E}+12$ & $1.88 \mathrm{E}+11$ & $1.41 \mathrm{E}+12$ \\
\hline 4 & 0.5 & 1 & 1 & 2 & 5 & $4.81 \mathrm{E}+08$ & $1.05 \mathrm{E}+08$ & $9.09 \mathrm{E}+07$ & $2.34 \mathrm{E}+14$ & $1.02 \mathrm{E}+14$ & $2.94 \mathrm{E}+13$ & $1.07 \mathrm{E}+15$ & $5.08 \mathrm{E}+13$ & $3.82 \mathrm{E}+14$ \\
\hline 4 & 0.5 & 1 & 1 & 2 & 6 & $7.91 \mathrm{E}+09$ & $1.72 \mathrm{E}+09$ & $1.50 \mathrm{E}+09$ & $6.32 \mathrm{E}+16$ & $2.75 \mathrm{E}+16$ & $7.96 \mathrm{E}+15$ & $2.91 \mathrm{E}+17$ & $1.37 \mathrm{E}+16$ & $1.03 \mathrm{E}+17$ \\
\hline 4 & 0.5 & 1 & 1 & 2 & 7 & $1.30 \mathrm{E}+11$ & $2.83 \mathrm{E}+10$ & $2.46 \mathrm{E}+10$ & $1.71 \mathrm{E}+19$ & $7.43 \mathrm{E}+18$ & $2.15 \mathrm{E}+18$ & $7.86 \mathrm{E}+19$ & $3.71 \mathrm{E}+18$ & $2.79 \mathrm{E}+19$ \\
\hline
\end{tabular}


Table 4.2: Values of $\mathrm{m}_{100}, \mathrm{~m}_{010}, \mathrm{~m}_{001} \mathrm{~m}_{110}, \mathrm{~m}_{101}, \mathrm{~m}_{011} \mathrm{~m}_{200}, \mathrm{~m}_{020}$, and $\mathrm{m}_{002}$ for varying values of $\boldsymbol{\mu}_{11}, \boldsymbol{\mu}_{21}, \boldsymbol{\mu}_{31}, \mathbf{N}_{\mathbf{0}}, \mathbf{M}_{\mathbf{0}}$ and $\mathbf{K}_{\mathbf{0}}$.

\begin{tabular}{|c|c|c|c|c|c|c|c|c|c|c|c|c|c|c|}
\hline & 21 & 31 & $\mathrm{~N}_{0}$ & $\mathbf{M}_{0}$ & $\mathbf{K}_{0}$ & $n_{100}$ & & $N_{01}$ & & $m_{1}$ & 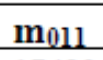 & & $\mathbf{m}_{020}$ & \\
\hline 0.21 & .3 & 0.5 & 400 & 200 & 100 & 6512 & 1437 & 1424 & 34040 & 8986 & 17430 & 85800 & 10180 & 58960 \\
\hline 0.22 & 3 & 0.5 & 400 & 200 & 100 & 448 & 426 & 419 & & & 7350 & 3000 & & 8180 \\
\hline 0.23 & 0.3 & .5 & 400 & 200 & 100 & & & & & & & & & \\
\hline 0.24 & 0.3 & 0 & 4 & 200 & 100 & & & & & & & & & \\
\hline 0.25 & 0 . & & 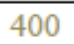 & 200 & 100 & & & & & & & & & \\
\hline 0.26 & 0 & & 400 & 200 & 100 & & & & & & & & & \\
\hline 0.2 & & ( & 400 & 200 & 100 & 6 & & & & $1 / 4$ & & & & 250 \\
\hline 0.2 & & .5 & 400 & 200 & 100 & 78 & 14 & & & 52 & & & & 760 \\
\hline 0.2 & & .5 & 0 & 200 & 100 & 78 & 39 & & & 29 & & & & 270 \\
\hline 0.2 & & .5 & 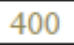 & 200 & 100 & 78 & & & & 07 & & & & 7790 \\
\hline 0.2 & & .5 & 400 & 200 & 100 & 878 & & & & 85 & & & & 7320 \\
\hline 0.2 & & .5 & 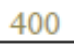 & 200 & 100 & & & & & 964 & & & & 50 \\
\hline 0.2 & 0. & 0.5 & 400 & 200 & 100 & 6 & 19 & & & 84 & & & & 30 \\
\hline 0.2 & 0 & & 400 & 200 & 100 & 6 & 144 & & & 9070 & & & & 70 \\
\hline 0.2 & 0 & & 400 & 200 & 100 & 6 & 1449 & & & 9057 & & & & 660 \\
\hline 0.2 & 0 & & 400 & 200 & 100 & 6578 & 14 & & & 90 & & & & 6400 \\
\hline 0.2 & & & 400 & 200 & 100 & & & & & 30 & & & & \\
\hline 0.2 & & & 4 & 200 & 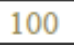 & & & & & 9016 & & & & 80 \\
\hline 0.2 & & & & 200 & 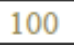 & & & & & & & & & 40 \\
\hline 0.2 & & & & 200 & 1 & & & & & & & & & 440 \\
\hline 0.2 & & & & 200 & 10 & & & & & & & & & 40 \\
\hline 0.2 & & & & 200 & - & 7 & & & & 100 & 50 & & & 490 \\
\hline 0.2 & & & & 200 & 100 & 7 & & & & 10230 & 00 & & & 5540 \\
\hline 0.2 & & & & 200 & 100 & 7 & & & & 10460 & 40 & & & 7580 \\
\hline 0.2 & & & 400 & 210 & 100 & 6 & - & & 20 & 9097 & 10 & & & 9390 \\
\hline 0.2 & 0 & & 400 & 220 & 100 & 6 & 4. & & 20 & 9097 & 10 & & & 7340 \\
\hline 0.2 & 0 & & 400 & 230 & 100 & 6 & 4 & & 20 & 9097 & 10 & & & 5300 \\
\hline 0.2 & 0 & 0 & 400 & 240 & 100 & 6 & 4. & & 0 & 9097 & 10 & & & 3250 \\
\hline 0.2 & 0 & & 400 & 250 & 10 & 6 & 57 & & 20 & 9097 & 10 & 0 & & 1200 \\
\hline 0.2 & 0 & 0. & 400 & 260 & 10 & 657 & 9 & & 20 & 9097 & 0 & 0 & & 1200 \\
\hline 0.2 & 0 & $-\pi$ & 400 & 200 & 11 & 6578 & 9 & 144 & 20 & 9097 & 10 & 0 & 0 & 9390 \\
\hline 0.2 & 0 & $-\pi$ & 400 & 200 & 12 & 6578 & 9 & 1462 & 20 & 9097 & 10 & 0 & 80 & 9390 \\
\hline 0.2 & 0 & 0 & 400 & 200 & 1 & 6578 & 19 & 1479 & 20 & 9097 & 10 & 0 & 80 & 9390 \\
\hline 0.2 & 0 & 0 & 400 & 200 & 140 & 6578 & 9 & 1495 & 20 & 9097 & 10 & 0 & 80 & 9390 \\
\hline 0.2 & 0 & 0 & 4 & 200 & 15 & 6578 & 14 & & & 9097 & 10 & & 80 & 9390 \\
\hline 0.2 & 0. & & & 0 & & 578 & 1449 & 1528 & 34520 & 9097 & 17510 & & 10280 & 9090 \\
\hline
\end{tabular}


Table 4.3: Values of $\mathrm{m}_{100}, \mathrm{~m}_{010}, \mathrm{~m}_{001} \mathrm{~m}_{110}, \mathrm{~m}_{101}, \mathrm{~m}_{011} \mathrm{~m}_{200}, \mathrm{~m}_{020}$, and $\mathrm{m}_{002}$ for varying values of $\lambda_{10}$, $\lambda_{20}, \lambda_{30}, \delta_{10}, \delta_{20}$ and $\mathrm{t}$.

\begin{tabular}{|c|c|c|c|c|c|c|c|c|c|c|c|c|c|c|}
\hline$\lambda_{10}$ & $\lambda_{20}$ & $\lambda_{30}$ & $\delta_{10}$ & $\delta_{20}$ & $t$ & $\mathbf{m}_{100}$ & $\mathbf{m}_{010}$ & $\mathbf{m}_{001}$ & $\mathbf{m}_{110}$ & $\mathbf{m}_{101}$ & $\mathbf{m}_{011}$ & $\mathbf{m}_{200}$ & $\mathbf{m}_{020}$ & $\mathbf{m}_{002}$ \\
\hline 0.51 & 1 & 2 & 4 & 3 & 1 & 8.178 & 107.706 & 2916 & 1.259 & -0.804 & -10400 & 10.111 & 81.128 & 3641000 \\
\hline$\lambda_{10}$ & $\lambda_{20}$ & $\lambda_{30}$ & $\delta_{10}$ & $\delta_{20}$ & $t$ & $\mathbf{m}_{100}$ & $\mathbf{m}_{010}$ & $\mathbf{m}_{001}$ & $\mathbf{m}_{10}$ & $\mathbf{m}_{101}$ & $\mathbf{m}_{011}$ & $\mathbf{m}_{200}$ & $\mathbf{m}_{020}$ & $\mathbf{m}_{002}$ \\
\hline 0.52 & 1 & 2 & 4 & 3 & 1 & 8.26 & 108.02 & 2918 & 1.331 & -0.758 & -10300 & 10.258 & 81.495 & 3674000 \\
\hline 0.53 & 1 & 2 & 4 & 3 & 1 & 8.343 & 108.335 & 2920 & 1.405 & -0.71 & -10210 & 10.407 & 81.869 & 3707000 \\
\hline 0.54 & 1 & 2 & 4 & 3 & 1 & 8.427 & 108.652 & 2922 & 1.48 & -0.661 & -10120 & 10.558 & 82.251 & 3739000 \\
\hline 0.55 & 1 & 2 & 4 & 3 & 1 & 8.512 & 108.971 & 2924 & 1.557 & -0.612 & -10040 & 10.711 & 82.641 & 3772000 \\
\hline 0.56 & 1 & 2 & 4 & 3 & 1 & 8.597 & 109.292 & 2926 & 1.635 & -0.561 & -9970 & 10.866 & 83.038 & 3804000 \\
\hline 5 & 1.3 & 2 & 4 & 3 & 1 & 8.097 & 133.375 & 3071 & 1.086 & 0.163 & 68370 & 9.967 & 100.738 & 7854000 \\
\hline 5 & 1.4 & 2 & 4 & 3 & 1 & 8.097 & 143.579 & 3127 & 1.04 & 0.644 & 26210 & 9.967 & 106.693 & 5247000 \\
\hline 5 & 1.5 & 2 & 4 & 3 & 1 & 8.097 & 154.676 & 3186 & 0.988 & 1.219 & 18450 & 9.967 & 111.474 & 4685000 \\
\hline 5 & 1.6 & 2 & 4 & 3 & 1 & 8.097 & 166.748 & 3248 & 0.929 & 1.907 & 15760 & 9.967 & 114.234 & 4427000 \\
\hline 5 & 1.7 & 2 & 4 & 3 & 1 & 8.097 & 179.885 & 3312 & 0.861 & 2.732 & 14820 & 9.967 & 113.743 & 4282000 \\
\hline 5 & 1.8 & 2 & 4 & 3 & 1 & 8.097 & 194.187 & 3379 & 0.785 & 3.725 & 14860 & 9.967 & 108.211 & 4197000 \\
\hline 5 & 1 & 2.1 & 4 & 3 & 1 & 8.097 & 107.395 & 3145 & 1.189 & -1.91 & -11380 & 9.967 & 80.768 & 4270000 \\
\hline 5 & 1 & 2.2 & 4 & 3 & 1 & 8.097 & 107.395 & 3397 & 1.189 & -2.928 & -12340 & 9.967 & 80.768 & 5058000 \\
\hline 5 & 1 & 2.3 & 4 & 3 & 1 & 8.097 & 107.395 & 3670 & 1.189 & -3.915 & -13390 & 9.967 & 80.768 & 5999000 \\
\hline 5 & 1 & 2.4 & 4 & 3 & 1 & 8.097 & 107.395 & 3968 & 1.189 & -4.884 & -14540 & 9.967 & 80.768 & 7121000 \\
\hline 5 & 1 & 2.5 & 4 & 3 & 1 & 8.097 & 107.395 & 4293 & 1.189 & -5.844 & -15790 & 9.967 & 80.768 & 8460000 \\
\hline 5 & 1 & 2.6 & 4 & 3 & 1 & 8.097 & 107.395 & 4646 & 1.189 & -6.806 & -17160 & 9.967 & 80.768 & 10060000 \\
\hline 5 & 1 & 2 & 4.02 & 3 & 1 & 7.936 & 107.2 & 2916 & 1.172 & -0.764 & -10860 & 9.763 & 80.29 & 3551000 \\
\hline 5 & 1 & 2 & 4.04 & 3 & 1 & 7.779 & 107.005 & 2918 & 1.155 & -0.68 & -11260 & 9.564 & 79.822 & 3491000 \\
\hline 5 & 1 & 2 & 4.06 & 3 & 1 & 7.625 & 106.812 & 2921 & 1.139 & -0.598 & -11690 & 9.369 & 79.365 & 3429000 \\
\hline 5 & 1 & 2 & 4.08 & 3 & 1 & 7.474 & 106.619 & 2923 & 1.122 & -0.517 & -11280 & 9.177 & 78.918 & 3364000 \\
\hline 5 & 1 & 2 & 4.10 & 3 & 1 & 7.326 & 106.427 & 2925 & 1.106 & -0.437 & -12720 & 8.99 & 78.48 & 3295000 \\
\hline 5 & 1 & 2 & 4.12 & 3 & 1 & 7.181 & 106.236 & 2927 & 1.09 & -0.359 & -13320 & 8.807 & 78.052 & 3221000 \\
\hline 5 & 1 & 2 & 4 & 3.02 & 1 & 8.097 & 105.881 & 2919 & 1.194 & -0.899 & -9734 & 9.967 & 80.522 & 3716000 \\
\hline 5 & 1 & 2 & 4 & 3.04 & 1 & 8.097 & 104.392 & 2924 & 1.199 & -0.946 & -9083 & 9.967 & 80.247 & 3818000 \\
\hline 5 & 1 & 2 & 4 & 3.06 & 1 & 8.097 & 102.927 & 2929 & 1.204 & -0.992 & -8525 & 9.967 & 79.945 & 3917000 \\
\hline 5 & 1 & 2 & 4 & 3.08 & 1 & 8.097 & 101.486 & 2934 & 1.209 & -1.035 & -8043 & 9.967 & 79.617 & 4012000 \\
\hline 5 & 1 & 2 & 4 & 3.10 & 1 & 8.097 & 100.069 & 2939 & 1.214 & -1.077 & -7624 & 9.967 & 79.265 & 4106000 \\
\hline 5 & 1 & 2 & 4 & 3.12 & 1 & 8.097 & 98.674 & 2944 & 1.218 & -1.117 & -7258 & 9.967 & 78.892 & 4197000 \\
\hline 5 & 1 & 2 & 4 & 3 & 2 & 0.164 & 13.625 & $2.00 \mathrm{E}+04$ & 0.07 & -0.532 & $-7.66 \mathrm{E}+03$ & 0.206 & 18.96 & $1.61 \mathrm{E}+08$ \\
\hline 5 & 1 & 2 & 4 & 3 & 3 & $3.32 \mathrm{E}-03$ & 1.545 & $1.34 \mathrm{E}+05$ & $1.53 \mathrm{E}-03$ & $-1.78 \mathrm{E}-01$ & $-5.66 \mathrm{E}+03$ & $4.17 \mathrm{E}-03$ & $2.46 \mathrm{E}+00$ & $7.21 \mathrm{E}+09$ \\
\hline 5 & 1 & 2 & 4 & 3 & 4 & $6.72 \mathrm{E}-05$ & 0.172 & $8.96 \mathrm{E}+05$ & $3.13 \mathrm{E}-05$ & $-1.10 \mathrm{E}-02$ & $-4.19 \mathrm{E}+03$ & $8.44 \mathrm{E}-05$ & $2.82 \mathrm{E}-01$ & $3.22 \mathrm{E}+11$ \\
\hline 5 & 1 & 2 & 4 & 3 & 5 & $1.36 \mathrm{E}-06$ & 0.019 & $5.99 \mathrm{E}+06$ & $6.34 \mathrm{E}-07$ & $-1.45 \mathrm{E}-03$ & $-3.10 \mathrm{E}+03$ & $1.71 \mathrm{E}-06$ & $3.10 \mathrm{E}-02$ & $1.44 \mathrm{E}+13$ \\
\hline 5 & 1 & 2 & 4 & 3 & 6 & $2.75 \mathrm{E}-08$ & $2.11 \mathrm{E}-03$ & $4.00 \mathrm{E}+07$ & $1.28 \mathrm{E}-08$ & $-1.96 \mathrm{E}-04$ & $-2.30 \mathrm{E}+03$ & $3.46 \mathrm{E}-08$ & $3.49 \mathrm{E}-03$ & $6.44 \mathrm{E}+14$ \\
\hline 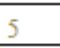 & 1 & 2 & 4 & 3 & 7 & $5.57 \mathrm{E}-10$ & $2.34 \mathrm{E}-04$ & $2.68 \mathrm{E}+08$ & $2.60 \mathrm{E}-10$ & $-2.65 \mathrm{E}-05$ & $-1.70 \mathrm{E}+03$ & $7.00 \mathrm{E}-10$ & $3.87 \mathrm{E}-04$ & $2.88 \mathrm{E}+16$ \\
\hline
\end{tabular}


Table 4.4: Values of $\mathrm{m}_{100}, \mathrm{~m}_{010}, \mathrm{~m}_{001} \mathrm{~m}_{110}, \mathrm{~m}_{101}, \mathrm{~m}_{011} \mathrm{~m}_{200}, \mathrm{~m}_{020}$, and $\mathrm{m}_{002}$ for varying values of $\boldsymbol{\mu}_{10}, \boldsymbol{\mu}_{20}, \boldsymbol{\mu}_{30}, \mathbf{N}_{\mathbf{0}}, \mathbf{M}_{\mathbf{0}}$ and $\mathbf{K}_{\mathbf{0}}$.

\begin{tabular}{|c|c|c|c|c|c|c|c|c|c|c|c|c|c|c|}
\hline$\mu_{10}$ & $\mu_{20}$ & $\mu_{30}$ & $\mathrm{~N}_{0}$ & $\mathbf{M}_{0}$ & $\mathbf{K}_{0}$ & $\mathbf{m}_{100}$ & $\mathbf{m}_{010}$ & $\mathbf{m}_{001}$ & $\mathbf{m}_{10}$ & $\mathbf{m}_{101}$ & $\mathbf{m}_{01}$ & $\mathbf{m}_{2 n n}$ & $\mathbf{m}_{020}$ & $\mathbf{m}_{002}$ \\
\hline 0.41 & 0.2 & 0.1 & 400 & 200 & 100 & 8.016 & 107.085 & 2912 & 1.177 & -0.805 & -10630 & 9.865 & 80.498 & 3574000 \\
\hline 0.42 & 0.2 & 0.1 & 400 & 200 & 100 & 7.936 & 106.777 & 910 & 1.166 & -0.76 & -10760 & 9.763 & 80.232 & \\
\hline 0.43 & 0.2 & 0.1 & 400 & 200 & 100 & 7.857 & 106.47 & 2908 & 1.155 & -0.717 & -10910 & 9.663 & 79.97 & 504000 \\
\hline 0.44 & 0.2 & 0.1 & 400 & 200 & 100 & 7.779 & 106.165 & 2906 & 1.144 & -0.673 & -11060 & \begin{tabular}{|l|}
9.564 \\
\end{tabular} & 79.712 & \\
\hline 0.45 & 0.2 & 0.1 & 400 & 200 & 100 & 7.702 & 105.862 & 2904 & .133 & -0.631 & & 9.466 & 79.458 & \\
\hline 0.46 & 0.2 & 0.1 & 400 & 200 & 100 & 7.625 & 105.561 & 2902 & 1.122 & -0.589 & -11390 & 9.369 & 79.208 & 3397000 \\
\hline 0.4 & 0.21 & 0.1 & 400 & 200 & 100 & 8.097 & 106.635 & 2909 & 191 & -0.875 & 0070 & \begin{tabular}{|l|}
9.967 \\
\end{tabular} & 30.649 & 000 \\
\hline 0.4 & 0.22 & 0.1 & 400 & 200 & 100 & 8.097 & 10 & 2904 & 94 & -( & 69 & 967 & 22 & 000 \\
\hline$\mu_{10}$ & $\mu_{20}$ & $\mu_{30}$ & $\mathrm{~N}_{0}$ & $\mathbf{M}_{0}$ & $\mathbf{K}_{0}$ & $\mathbf{m}_{100}$ & n & $\mathbf{m}_{001}$ & $\mathbf{m}_{10}$ & $\mathbf{m}_{101}$ & $\mathbf{m}_{011}$ & $\mathrm{n}_{200}$ & 1020 & \\
\hline 0.4 & 0.23 & 0.1 & 400 & 200 & 100 & 8.097 & & 2899 & 197 & & & 967 & 388 & \\
\hline 0.4 & 0.24 & 0.1 & 400 & 200 & 100 & 8.097 & 104.392 & 2894 & 1.199 & 946 & & .967 & 247 & 000 \\
\hline 0.4 & 0.25 & 0.1 & 400 & 200 & 100 & 8.097 & 103 & 2893 & 202 & 969 & & 967 & .099 & \\
\hline 0.4 & 0.26 & 0.1 & 400 & 200 & 100 & 8.097 & 102.927 & 2885 & 1.204 & -0.992 & -8356 & 9.967 & 79.945 & 000 \\
\hline 0.4 & 0.2 & 0.11 & 400 & 200 & 100 & 8.097 & & 2892 & & & & 67 & 768 & \\
\hline 0.4 & 0.2 & 0.12 & 400 & 200 & 100 & 8.097 & & 2870 & 89 & & & 67 & 768 & \\
\hline 0.4 & 0.2 & 0.13 & 400 & 200 & 100 & 8.097 & 10 & 2848 & 89 & 21 & & 67 & 68 & \\
\hline 0.4 & 0.2 & 0.14 & 400 & 200 & 100 & 8.097 & 10 & 2827 & 89 & -0.411 & & 67 & 768 & \\
\hline 0.4 & 0.2 & 0.15 & 400 & 200 & 100 & 8.097 & 107 & 2805 & 89 & 99 & & 67 & 768 & \\
\hline 0.4 & 0.2 & 0.16 & 400 & 200 & 100 & 8.097 & & 2784 & & & & 67 & 768 & \\
\hline 0.4 & 0.2 & 0.1 & 410 & 200 & 100 & 8.299 & 109 & 2946 & 1.218 & -0.871 & 50 & 10.216 & 82.563 & 00 \\
\hline 0.4 & 0.2 & 0.1 & 420 & 200 & 100 & 8.502 & & 2978 & 248 & -0.892 & & 0.465 & 358 & \\
\hline 0.4 & 0.2 & 0.1 & 430 & 200 & 100 & 8.704 & & 3010 & 1.278 & -0.914 & & 10.714 & 153 & \\
\hline 0.4 & 0.2 & 0.1 & 440 & 200 & 100 & 8.906 & & 3042 & & & & & 949 & \\
\hline 0.4 & 0.2 & 0.1 & 450 & 200 & 100 & 9.109 & 118 & 3074 & 37 & -0.956 & & 213 & 89.744 & 00 \\
\hline 0.4 & 0.2 & 0.1 & 460 & 200 & 100 & 9.311 & & 3106 & 67 & -0.977 & & 462 & 539 & \\
\hline 0.4 & 0.2 & 0.1 & 400 & 210 & 100 & 8.097 & 108.503 & 2962 & 1.189 & -0.85 & 0 & .967 & .215 & \\
\hline 0.4 & 0.2 & 0.1 & 400 & 220 & 100 & 8.097 & & 3010 & 1.189 & & & 9.967 & 663 & 000 \\
\hline 0.4 & 0.2 & 0.1 & 400 & 230 & 100 & 8.097 & & 3058 & & & & & & \\
\hline 0.4 & 0.2 & 0.1 & 400 & 240 & 100 & 8.097 & 111.827 & 3106 & 1.189 & -0.85 & -10500 & 9.967 & 82.559 & 0000 \\
\hline 0.4 & 0.2 & 0.1 & 400 & 250 & 100 & 8.097 & 112.935 & 3154 & 1.189 & -0.85 & & 9.967 & 83.007 & 1000 \\
\hline 0.4 & 0.2 & 0.1 & 400 & 260 & 100 & 8.097 & 114.043 & 3203 & 1.189 & -0.85 & -10490 & 9.967 & 83.455 & 4871000 \\
\hline 0.4 & 0.2 & 0.1 & 400 & 200 & 110 & 8.097 & 107.395 & 2981 & 1.189 & -0.85 & -10500 & 9.967 & 80.768 & 3608000 \\
\hline 0.4 & 0.2 & 0.1 & 400 & 200 & 120 & 8.097 & 107.395 & 3048 & 1.189 & -0.85 & -10500 & 9.967 & 80.768 & 3609000 \\
\hline 0.4 & 0.2 & 0.1 & 400 & 200 & 130 & 8.097 & 107.395 & 3114 & 1.189 & -0.85 & -10500 & 9.967 & 80.768 & 3609000 \\
\hline 0.4 & 0.2 & 0.1 & 400 & 200 & 140 & 8.097 & 107.395 & 3181 & 1.189 & -0.85 & & 9.967 & 80.768 & 3610000 \\
\hline 0.4 & 0.2 & 0.1 & 400 & 200 & 150 & 8.097 & 107.395 & 3248 & 1.189 & -0.85 & -10500 & 9.967 & 80.768 & 3610000 \\
\hline 0.4 & 0.2 & 0.1 & 400 & 200 & 160 & 8.097 & 107.395 & 3315 & 1.189 & -0.85 & -10500 & 9.967 & 80.768 & 3610000 \\
\hline
\end{tabular}

\section{References:}

[1]. Abundo, M., Rossi, C.: Numerical Simulation of a stochastic model for cancerous cells submitted to chemotherapy. Journal of Mathematical Biology. 27, 81-90 (1989)

[2]. Birkhead, B.G., Gregory, W.M.: A Mathematical model of the effect of drug resistance in cancer chemotherapy. Math. Biosci. 72, 59-69 (1984)

[3]. Coldman, A.J., Goldie, J.H.: A model for the resistance of tumor cells to cancer chemotherapeutic agents. Math. Biosci. 65, 291-307 (1983)

[4]. Coldman, A.J., Goldie, J.H.: A stochastic model for the origin and treatment of tumors containing drug resistant cells. Bull. Math. Biol. 48, 279-292 (1986)

[5]. Costa, M.I.S., Boldrini, J. L., Bassanezi, R.C.: Chemotherapeutic Treatments Involving Drug Resistance and Level of Normal Cells as a Criterion of Toxicity. Mathematical Biosciences. 125, 211-228 (1995)

[6]. John Carl Panetta.: A mathematical model of drug resistance: Heterogeneous tumors. Mathematical Biosciences. 147, 41-61 (1998) 
[7]. Sandeep Sanga, John P Sinek, Hermann B Frieboes, Mauro Ferrari, John P Fruehauf, Vittorio Cristini.: Mathematical modeling of Cancer progression and response to chemotherapy. Expert Rev. Anticancer Ther. 6(10), 1361-1376 (2006)

[8]. Srinivasa Rao, K., Tirupathi Rao, P.: A Stochastic Model for Cancer Cell Growth under Chemotherapy. Assam Statistical Review. 18(1), 81-101 (2004)

[9]. Srinivasa Rao, K., Tirupathi Rao, P.: Stochastic Model for Mutant Cell Growth with Inactivation of Allele Genes. Journal of Statistical Theory and Applications. 3(1), 75-85 (2004)

[10]. Tirupathi Rao, P., Srinivasa Rao, K.: Stochastic Model for Cancer Cell Growth with Spontaneous Mutation and Proliferation. International Journal of Management and Systems. 20(1), 85-93 (2004)

[11]. Tirupathi Rao, P., Madhavi, K., Masthan Babu, S.K.: Bivariate Stochastic Modeling for Mutant Cell Growth under Chemotherapy. International Journal of Mathematics and applications. 4(1), 1-12 (2011) 